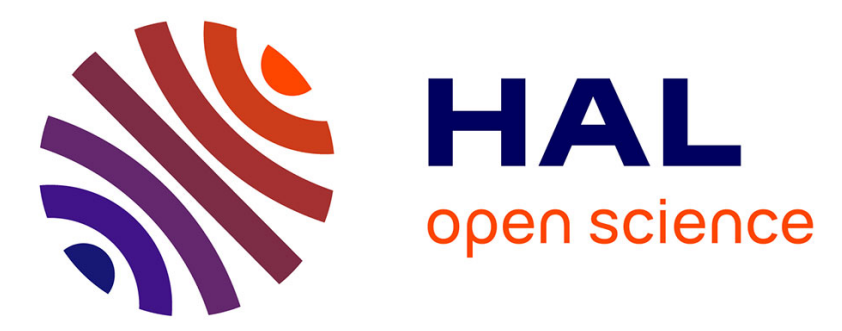

\title{
Iodinated polymer nanoparticles as contrast agent for spectral photon counting computed tomography
}

Joëlle Balegamire, Marc Vandamme, Emmanuel Chereul, Salim Si-Mohamed, Samira Azzouz Maache, Eyad Almouazen, Laurent Ettouati, Hatem Fessi, Loic Boussel, Philippe Douek, et al.

\section{To cite this version:}

Joëlle Balegamire, Marc Vandamme, Emmanuel Chereul, Salim Si-Mohamed, Samira Azzouz Maache, et al.. Iodinated polymer nanoparticles as contrast agent for spectral photon counting computed tomography. Biomaterials Science, 2020, 8 (20), pp.5715-5728. 10.1039/D0BM01046D . hal-02946431

\section{HAL Id: hal-02946431 \\ https://hal.science/hal-02946431}

Submitted on 2 Dec 2020

HAL is a multi-disciplinary open access archive for the deposit and dissemination of scientific research documents, whether they are published or not. The documents may come from teaching and research institutions in France or abroad, or from public or private research centers.
L'archive ouverte pluridisciplinaire HAL, est destinée au dépôt et à la diffusion de documents scientifiques de niveau recherche, publiés ou non, émanant des établissements d'enseignement et de recherche français ou étrangers, des laboratoires publics ou privés. 


\section{lodinated polymer nanoparticles as contrast agent for Spectral Photon Counting Computed Tomography}

Received 00th January 20xx, Accepted 00th January 20xx DOI: $10.1039 / x 0 x \times 00000 x$

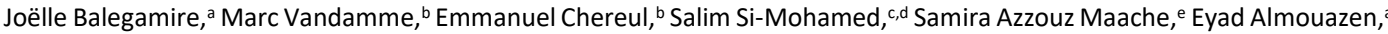 \\ Laurent Ettouati, ${ }^{f}$ Hatem Fessi, ${ }^{a}$ Loïc Boussel, ${ }^{c, d}$ Philippe Douek, ${ }^{c, d}$ Yves Chevalier ${ }^{\mathrm{a}, *}$
}

\section{Introduction}

Recent progresses in the technology of X-ray tomography allow more elaborated investigations in the cardiovascular system, far beyond classical angiography by first pass imaging with contrast agents showing fast clearance. Spectral Photon Counting CT

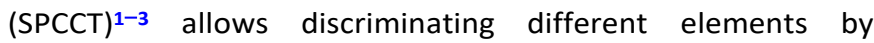
recording the X-ray energy spectrum of tissues attenuation at each voxel, resulting in 'multicolor' images. ${ }^{1-9}$ Measurement of the $\mathrm{K}$ absorption line of the contrast agent provides a specific image that is free of the background attenuation by the surrounding tissues. ${ }^{2}$ Reduction of spectral data of mixed contrast agents by 'Material Decomposition' and 'K-edge reconstruction' methods provides specific images and quantitative determination of the concentration of each specific element. ${ }^{10-12}$ Imaging over long periods or labelling specific tissues requires that contrast agents circulate in the blood stream for long enough duration. Too fast clearance, either by renal elimination or by uptake through the immune system should be avoided. To these ends, new contrast agents are being developed, in particular concentrated suspensions of nanoparticles. ${ }^{13}$

a. University of Lyon 1, LAGEPP, CNRS UMR 5007, 69622 Villeurbanne, France. b. VOXCAN, 69280 Marcy-L'Étoile, France.

c. University Lyon 1, CREATIS, CNRS UMR 5220, INSERM U630, 69621 Villeurbanne, France.

d. Hospices Civils de Lyon, Radiology Department, 69677 Bron, France.

e. University of Lyon 1, ISPB, Department of Parasitology and Medical Mycology, 69008 Lyon, France.

f. University of Lyon 1, ISPB, B2MC, 69373 Lyon, France.
So far, iodine-based materials are the most widely used contrast agents for X-ray imaging. Contrast agents currently used in clinical radiology are small iodinated molecules that have very short circulation half-lives and might show renal toxicity. ${ }^{14}$ Contrast agents in the form of nanoparticles may overcome these drawbacks. ${ }^{4,15-17}$ Expected benefits of such contrast agents with respect to current solutions of small molecules are a high iodine concentration while retaining a low viscosity, and a specific measurement of biodistribution after injection. In addition to providing a higher payload of radiopaque elements in a single nanomaterial, ${ }^{9}$ the latter may be given a tunable surface with targeting biomarkers that can bind to specific sites. Binding of nanoparticles obviously provides much higher contrast than small molecules. Furthermore, organic iodinated particles can be loaded with active ingredients (drugs) in the framework of theranostic applications.

The specifications of nanoparticulate systems are a small size and a suitable biocompatibility of the surface of nanoparticles. A very small size (less than $5 \mathrm{~nm}$ ) allows nanoparticles to pass through 'filters' of the glomerular basement membrane, ${ }^{18}$ leading to fast clearance by renal elimination. Large particles (larger than $500 \mathrm{~nm}$ ) can cause embolization of the narrowest capillaries. In the suitable window for long-time circulation, nanoparticles are taken up in the liver and spleen by the macrophages of the mononuclear phagocytes system (MPS). As macrophages uptake is more efficient for large nanoparticles, ${ }^{19}$ it is advisable to consider small enough size of nanoparticles; a size between $20 \mathrm{~nm}$ and $200 \mathrm{~nm}$ appears favorable. In addition, a stealth agent is implemented at the surface of nanoparticles in order to avoid detection by macrophages and increase 
circulation time in the blood stream. This is achieved by coating the nanoparticle surface with a dense layer of hydrophilic polymer material; the most popular is poly(ethylene glycol) (PEG). Finally, it is not possible to record attenuation of the iodine element in the energy range of its low K-edge (33.2 keV) because tissues absorption is too high. CT scanners do not work at such low energies. lodine-based nanomaterials are widely used and they are still considered useful as contrast agents for the SPCCT technology. Quantification of iodine can be done by the 'Material Decomposition' method. Elements having their Kabsorption in the right range are essentially heavy elements. ${ }^{20}$ Various types of iodinated nanosystems for CT imaging have been reported in the literature (i.e. dendrimers, ${ }^{\mathbf{2 1 , 2 2}}$ liposomes, ${ }^{23}$ block copolymer micelles, ${ }^{24-26}$ emulsions, ${ }^{27-29}$ organic nanoparticles ${ }^{30-32}$ ) together with their preparation processes. ${ }^{33-35}$ Special focus is presently made on polymeric nanoparticles that show much better stability and resistance to various stimuli. Two main strategies are commonly used to manufacture polymeric nanoparticles: polymerization of monomers which is a two-step process that includes techniques such as emulsion polymerization, ${ }^{36,37}$ dispersion polymerization, ${ }^{38}$ micellar polymerization (also known as inverse microemulsion polymerization), ${ }^{39}$ and interfacial polymerization. ${ }^{40}$ The second fabrication route involves dispersion of a preformed polymer using various processes: emulsion-solvent evaporation, emulsification-solvent diffusion, salting-out, and nanoprecipitation (or solvent displacement). ${ }^{41}$ The aim of this study is to design an iodine-based contrast agent for CT and SPCCT imaging, in the form of polymeric nanoparticles of $20-200 \mathrm{~nm}$ size range. Preformed polymers can be made radiopaque by covalently grafting an iodinecontaining moiety onto the macromolecular structure, thus preventing possible iodine leakage. ${ }^{42}$ The nanoprecipitation process was chosen for nanoparticle fabrication as it is a onestep process yielding nanoparticles and it does not require high energy. Physicochemical characterizations of the iodinated polymer (iodine content, crystallinity, etc.) and the nanoparticles (size, morphology, stability) were performed. Xray radiopacity of iodinated polymer nanoparticles was investigated in vitro on phantoms and in vivo by intravenous injection to rats and $\mathrm{CT}$ imaging them. The potential of the SPCCT technology in terms of in vitro element quantification and discrimination of several contrasting elements within a single scan was also assessed.

\section{Results and discussion}

Synthesis and characterization of iodinated polymer (TIB-PVAL)

\section{Grafting reaction and ${ }^{1} \mathrm{H}$ NMR analysis}

Attachment of triiodobenzoyl graft to the PVAL backbone (Figure 1) was performed by reacting the corresponding acid chloride with the alcohol groups of PVAL in dry NMP solvent, thus creating strong covalent ester bonds. Acid chloride was used in large excess with respect to the hydroxyl groups of PVAL. Several purification steps by dissolution in THF and recrystallization in ethanol were necessary in order to remove unreacted triiodobenzoyl chloride. These steps were repeated until all the corresponding peaks no longer appeared on the ${ }^{1} \mathrm{H}$ NMR spectra. Considering the slow molecular motions of polymers, the grafted iodinated aromatic moieties appeared as broad peaks at $\delta=7.61 \mathrm{ppm}$ and $\delta=8.23 \mathrm{ppm}$ (Figure 1). Conversely, unreacted iodinated reagents mixed with the grafted polymer appeared as sharp peaks at $\delta=7.76 \mathrm{ppm}$ and $8.34 \mathrm{ppm}$. The absence of sharp peaks in the NMR spectrum showed that the concentration of residual small molecular impurities was lower that the detection limit of ${ }^{1} \mathrm{H}$ NMR.

\section{Degree of substitution and iodine content}

The degree of substitution (DS) or grafting rate (Equation 1), was calculated from the integrals of the 2 phenyl protons specific to the grafted PVAL ( $\mathrm{CH}$ between 7.5 and $8.5 \mathrm{ppm}$ ) with respect to integrals of protons of the PVAL backbone $\left(\mathrm{CH}_{2}\right.$ between 1.3 and $2.5 \mathrm{ppm}$ or $\mathrm{CHOH}$ between 3.5 and $5.5 \mathrm{ppm}$ ) (Figure 1).

$D S=\frac{x}{x+y}=\frac{I(\mathrm{CH})_{7.5-8.5 p m}}{I\left(\mathrm{CH}_{2}\right)_{1.3-2.5 p m}}$

$D S$ was calculated with better accuracy from the integrals of the backbone $\mathrm{CH}_{2}$ between 1.3 and $2.5 \mathrm{ppm}$. The substitution degree of TIB-PVAL $13 \mathrm{kDa}$ was $D S=0.77$. The specific iodine content (mass fraction of iodine) was calculated from the degree of substitution according to Equation 2,

$\mathrm{wt} \%(\mathrm{I})=\frac{D S \times M_{\mathrm{mol}}(\text { Iodine }) \times n}{M_{\mathrm{mol}}(\mathrm{PVAL}) \times(1-D S)+M_{\mathrm{mol}}(\mathrm{TIB}-\mathrm{PVAL}) \times D S}$

where $M_{\text {mol }}$ (lodine) $=127 \mathrm{~g} \cdot \mathrm{mol}^{-1}$ is the molar mass of iodine atom, $n=3$ is the number of iodine atoms per benzoyl group, $M_{\text {mol }}(\mathrm{PVAL})=44 \mathrm{~g} \cdot \mathrm{mol}^{-1}$ is the molar mass of non-grafted PVAL repeat unit, and $M_{\mathrm{mol}}(\mathrm{TIB}-\mathrm{PVAL})=526 \mathrm{~g} \cdot \mathrm{mol}^{-1}$ is the molar mass of the grafted repeat unit. $D S=77 \%$ determined by ${ }^{1} \mathrm{H} N M R$ analysis gave $71 \mathrm{wt} \%$ of iodine. This experimental value was very close to the theoretical iodine concentration that would have been reached, i.e. $72 \mathrm{wt} \%$, for $100 \%$ conversion of the grafting reaction $(D S=1)$. The very high iodine content determined by ${ }^{1} \mathrm{H}$ NMR was confirmed by ICP-OES analysis for iodine which gave an iodine content of $69 \mathrm{wt} \%$. This high iodine content is found each time the triiodobenzoyl moiety is densely

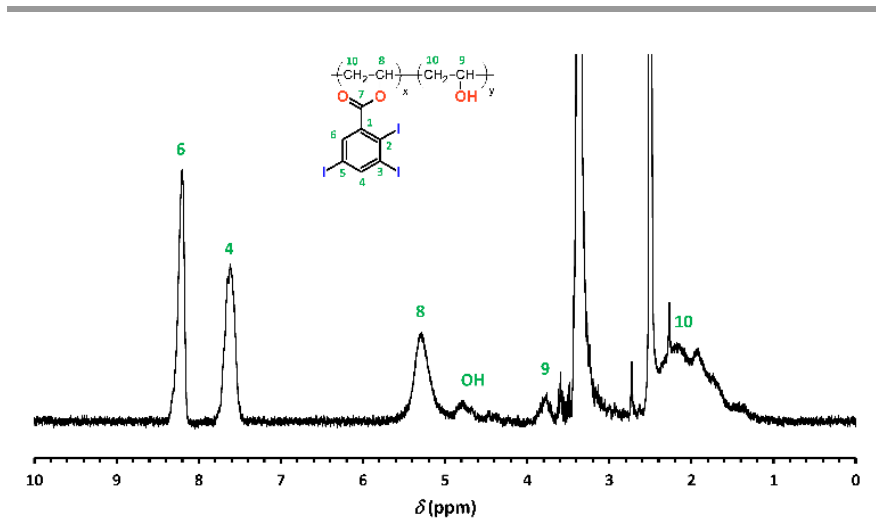

Figure 1. ${ }^{1} \mathrm{H}$ NMR spectrum of TIB-PVAL, the modified PVAL with a radiopaque triiodobenzoyl moiety in DMSO- $d 6$. 
attached to a polymer backbone. As example the iodine content is $62.3 \mathrm{wt} \%$ for an ester of TIB and poly(hydroxyethylmethacrylate) referred to as poly(MAOTIB), ${ }^{32}$ of the same order of magnitude though slightly less than in our case. High iodine content is mandatory for application to CT contrast agents because of the need for high iodine concentration of aqueous nanoparticle suspensions together with low viscosity that ensures syringeability. High iodine contents of 55.5 to 60.4 wt\% could also be reached in block copolymers bearing aliphatic iodine on their hydrophobic polycarbonate block. ${ }^{25,26}$

\section{Thermal analysis and X-ray diffraction}

Thermogravimetric analysis (TGA) showed that onset of thermal degradation the iodinated polymer was at around $230{ }^{\circ} \mathrm{C}$. Differential Scanning Calorimetry (Figure $2 \mathrm{~A}$ ) revealed one transition of small amplitude better corresponding to a glass transition than a melting. The glass transition temperature was determined at $T_{\mathrm{g}}=153^{\circ} \mathrm{C}$. Note that $T_{\mathrm{g}}$ of the non-grafted PVAL is around $85{ }^{\circ} \mathrm{C}$. No other phase transition was observed in the temperature range studied (i.e. below temperature of thermal degradation).

X-ray crystallography (Figure 2B) did not show crystalline peaks; a broad scattering peak was observed between $2 \vartheta=20-30^{\circ}$, which was typical of an amorphous material. Therefore, the polymer was considered fully glassy below $T_{\mathrm{g}}$. This is a favorable property, should any encapsulation of active molecules be considered in future studies.

\section{lodinated polymer nanoparticles: physicochemical characterization}

\section{Nanoparticles size, morphology and stability}

Aqueous dispersions of iodinated polymer nanoparticles were prepared using the nanoprecipitation process. A solution of TIBPVAL iodinated polymer and PCL- $b$-PEG dispersing agent in THF was poured into water under magnetic stirring, causing the precipitation of the polymer and dispersing agent as nanoparticles. THF was subsequently evaporated. This was followed by a concentration step by means of centrifugation/ redispersion. Dynamic Light Scattering (DLS) and Transmission Electron Microscopy (TEM) allowed measurements of particle sizes and morphology assessments at each preparation step. The main parameters that control the nanoprecipitation process are: the dispersing agent/iodinated polymer ratio (PCL$b$-PEG/TIB-PVAL), the THF/water ratio and the polymer
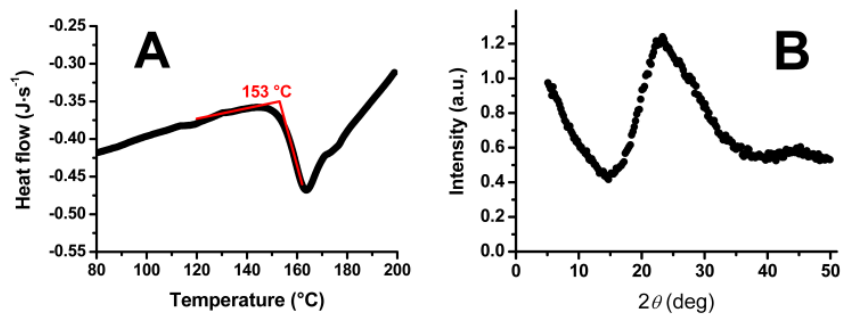

Figure 2. DSC scan (A) and X-ray diffraction (B) of TIB-PVAL. concentration in THF. As outcome of preliminary experiments, the PCL- $b$-PEG/TIB-PVAL weight ratio was set as $1 / 1$. This ratio was considered as optimum because the size distribution of nanoparticles was broad for lower ratio. The lowest concentration of PCL-b-PEG allowing formation of nearly monodisperse nanoparticles corresponded to a $1 / 1$ mass ratio. Excess block copolymer was present as shown later in this paper; but excess block copolymer micelles could not be detected by DLS as they were mixed with iodinated nanoparticles of larger size and refractive index. In case of a higher ratio, an excess of free block copolymer micelles was detected by DLS as a supplementary population of $30 \mathrm{~nm}$ size. According to Foncesca et al. ${ }^{43}$, doubling the aqueous phase volume significantly decreases the size of nanoparticles. Indeed, larger amount of water in the water/THF mixture decreases the solubility of the polymer. Thus, the THF/water volume ratio was set to $1 / 2$ based on literature reports.

Finally, the iodinated polymer concentration in the organic phase was optimized, keeping in mind that high iodine concentrations up to $100 \mathrm{mg}(\mathrm{I}) \cdot \mathrm{mL}^{-1}$ must be reached in the final injectable product. Particle size increased with respect to the concentration of iodinated polymer in THF (Figure 3). This trend is correlated to other reports of the literature. ${ }^{44-46}$ The highest concentration of iodinated polymer in THF yielding nanoparticles was $40 \mathrm{mg}(\mathrm{I}) \cdot \mathrm{mL}^{-1} \quad\left(17 \mathrm{mg}(\mathrm{I}) \cdot \mathrm{mL}^{-1}\right.$ final concentration in water). At this concentration, the particle size was below $200 \mathrm{~nm}$ using DLS. Above this concentration of PCL$b$-PEG/TIB-PVAL mixture is not soluble in THF, so that the large particles already present in THF formed a cloudy coarse dispersion that underwent fast sedimentation.

In order to concentrate the sample and reach suitable iodine content for in vivo studies without increasing particle size, or broadening the particle size distribution, a centrifugation/redispersion step was implemented. Centrifugation rate of $7,830 \mathrm{rpm}$ for $20 \mathrm{~min}$ was the minimum speed allowing full sedimentation of the particles (clear

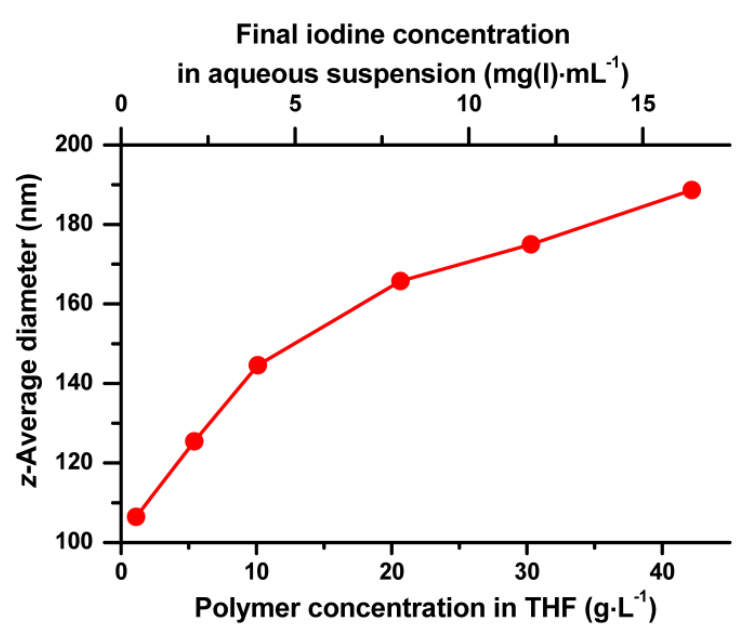

Figure 3. Variation of nanoparticles $z$-average diameter (from DLS) against iodinated polymer concentration in the organic solvent (THF). The top scale of iodine concentration in the final suspension is calculated from the materials balance of the process. The actual concentration was slightly lower because of materials loss during sample handling. 
supernatant). Under this condition, nanoparticles could easily be redispersed in water using simple ultrasonic bath. The optimized experimental conditions are given in Table 1.

The iodine content was increased by a factor of 5.5 without altering nanoparticle size, so as to reach high enough concentration for in vivo tests. TEM pictures in Figure 4A, B show monodisperse and spherical nanoparticles before and after the concentration step. The narrow particle size distribution observed by DLS supports these results (Figure 4C). A slight increase of mean diameter was observed which came from the size distribution broadening at its large particle size side. This is characteristic of an aggregation process where larger particles appeared but the smallest particles are still present. Note that the particle sizes measured from TEM pictures are smaller than those measured by DLS. Indeed, TEM operates an observation of the sample in its dry state whereas DLS measurements are performed with aqueous suspensions. Water molecules are associated with the particles and the PEG
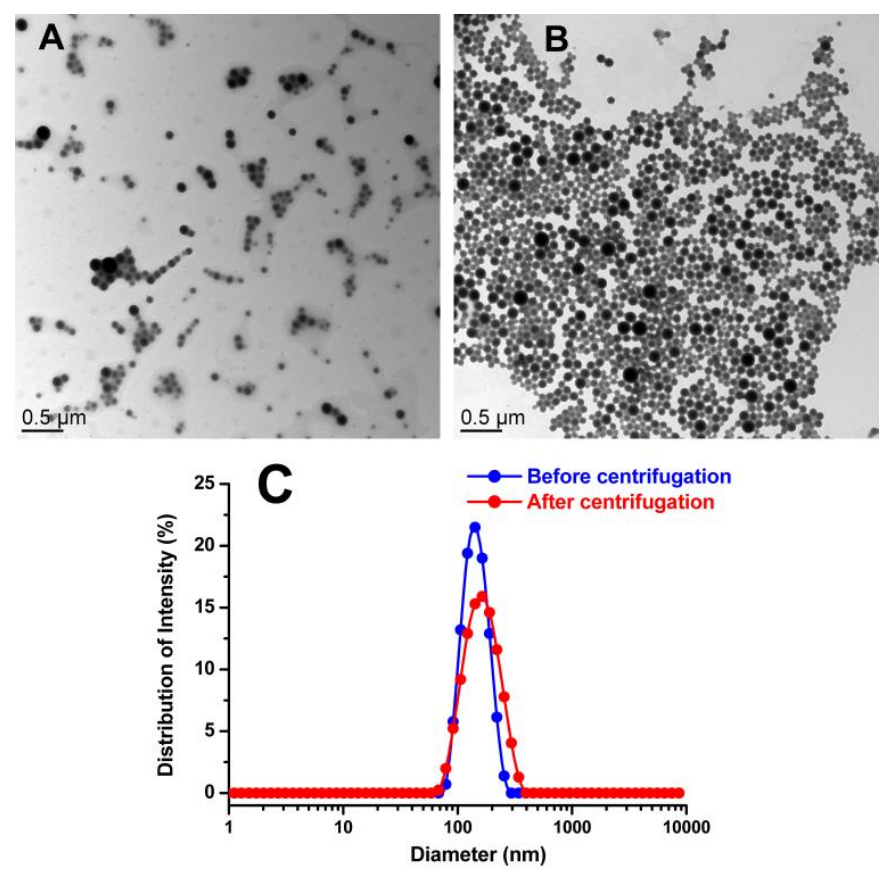

Figure 4. TEM pictures of TIB-PVAL nanoparticles before (A), after (B) centrifugation/redispersion and (C) particle size distribution from CONTIN analysis of DLS.

Table 1. Optimized parameters of centrifugation and redispersion for the preparation of concentrated suspensions of iodinated polymer nanoparticles in water.

\begin{tabular}{|c|c|c|}
\hline & $\begin{array}{l}\text { Centrifugation } \\
\text { parameters }\end{array}$ & $\begin{array}{l}\text { Redispersion } \\
\text { parameters }\end{array}$ \\
\hline Volume & $10 \mathrm{~mL}$ of suspension & $1 \mathrm{~mL} \mathrm{H}{ }_{2} \mathrm{O}$ \\
\hline Instrument & $\begin{array}{l}\text { Eppendorf centrifuge } \\
5430\end{array}$ & Ultrasonic bath \\
\hline Experimental conditions & $20 \mathrm{~min}$ at $7,830 \mathrm{rpm}$ & $90 \mathrm{~min}$ at $40^{\circ} \mathrm{C}$ \\
\hline $\begin{array}{l}\text { Mean particle diameter } \\
\text { (TEM) }\end{array}$ & $d=118 \mathrm{~nm}$ & $d=122 \mathrm{~nm}$ \\
\hline $\begin{array}{l}\text { z-Average particle } \\
\text { diameter (DLS) }\end{array}$ & $d=147 \mathrm{~nm}$ & $d=169 \mathrm{~nm}$ \\
\hline $\begin{array}{l}\text { Concentration of iodine } \\
\text { (ICP-OES) }\end{array}$ & $17 \mathrm{mg}(\mathrm{I}) \cdot \mathrm{mL}^{-1}$ & $98.8 \mathrm{mg}(\mathrm{I}) \cdot \mathrm{mL}^{-1}$ \\
\hline
\end{tabular}

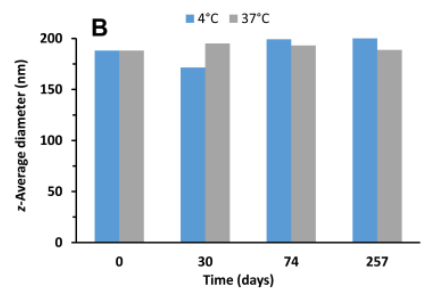

Figure 5. Stability of iodinated polymer nanoparticles in water at 4, 20 and $37^{\circ} \mathrm{C}(\mathrm{A})$ and in human serum at $4{ }^{\circ} \mathrm{C}$ and $37^{\circ} \mathrm{C}(\mathrm{B})$.

layer is swollen, so that the hydrodynamic size is retrieved. The hydrodynamic diameter is in excess with respect to the dry diameter by twice the thickness of the PEG layer.

Stability of the suspensions was assessed by monitoring nanoparticles size by DLS with respect to storage time. The mean diameter of nanoparticles was kept constant for the whole measurement period (Figure 5). Nanoparticles were stable and remained well-separated for over 8 months in water at 4,20 and $37^{\circ} \mathrm{C}$ and in human serum at 4 and $37^{\circ} \mathrm{C}$.

\section{Quantification of PEG on nanoparticles surface}

lodinated polymer nanoparticles were stabilized by the diblock poly(caprolactone)-block-poly(ethylene glycol) ( $\mathrm{PCL}_{65}-b$ $\left.\mathrm{PEG}_{113}\right)$. A core/shell structure is expected with a core made of iodinated polymer, the hydrophobic part of the dispersing agent (poly(caprolactone)) adsorbed onto the core, and the hydrophilic PEG part forming a water-swollen PEGylated shell. It is known that the presence of a PEG layer, not only increases stability by steric repulsion, but also enables particle furtivity in vivo by avoiding opsonization (absorption of recognition proteins from the immune system) or/and by preventing rapid recognition by macrophages from Kupffer cells. ${ }^{47,48}$ Another advantage of using polymers as stabilizing agents is enabling high surface coverage, leading to even more stable dispersions. ${ }^{49}$

Although PEG has been widely used as stabilizing agent of nanoparticles in life sciences for over 20 years and is approved by FDA for in vivo applications, there is no straightforward method to detect its presence on the particles surface and determine surface coverage. PEG chain coverage, conformation of the PEG layer, type of incorporation (either grafted or adsorbed) are important parameters that have been presently evaluated.

Here, dry extract and ${ }^{1} \mathrm{H}$ NMR spectroscopy measurements were combined to quantify the density of PEG at the surface of nanoparticles. The concentrations were determined by measuring a dry extract of a $10 \mathrm{~mL}$ part of the dispersion before centrifugation. As a reminder, in the initial sample $1 \mathrm{~g}$ of iodinated polymer and $1 \mathrm{~g}$ of dispersing agent were dissolved in $25 \mathrm{~mL}$ of THF, dispersed by mixing with $50 \mathrm{~mL}$ of water, and THF was subsequently removed. Therefore, the concentration of all initial compounds was $20 \mathrm{~g} \cdot \mathrm{L}^{-1} .0 .41 \mathrm{~g}$ of dry product was obtained upon drying $10 \mathrm{~mL}$ of dispersion, which closely corresponded to the expected sum of the dry extracts of TIBPVAL and PCL- $b$-PEG.

After a centrifugation/redispersion step under the operating conditions given in Table 1, most of unbound PEG was removed 
with the supernatant. DLS measurements showed that nonadsorbed PCL- $b$-PEG was in the form of block copolymer micelles of size $30 \mathrm{~nm}$ dispersed in the aqueous phase. Therefore, after centrifugation dry extracts of the supernatant and the wet sediment were also separately performed. One step of centrifugation was enough for removing the whole nonadsorbed materials since after redispersion in $10 \mathrm{~mL}$ pure water and a second centrifugation, no product was recovered in the dry extract of the supernatant. Such measurement meant that water remaining in the wet sediment was hydration water of the PEG shell only. There was no free PCL- $b$-PEG trapped in between the TIB-PVAL nanoparticles in the sediment.

According to Table 2, only $0.02 \mathrm{~g}$ of the dispersing agent was adsorbed to iodinated polymer nanoparticles. The rest has been removed with the supernatant in the form of block copolymer micelles. One might consider that since less than $10 \%$ of dispersing agent was adsorbed, this amount should be enough to stabilize the system both upon long term storage and during the preparation of the nanoparticles. This was actually not the case as preliminary tests made with dispersing agent/iodinated polymer mass ratios lower than $1 / 1$, yielded unstable suspensions and/or dispersions of polydisperse particles. So, a large excess of free PCL- $b$-PEG was required in order to stabilize nanoparticles in the mixed THF-water medium during the preparation process. Indeed, dynamics of block copolymers involved in micelles are slow; ${ }^{50}$ therefore, their adsorption to newly precipitated nanoparticles in slow during the preparation process. Since the formation of small and non-aggregated particle requires a fast stabilization during the preparation, a large concentration of block copolymer was used to compensate for the slow dynamics of adsorption.

Samples before and after centrifugation and both supernatant and pellet, were analyzed on ${ }^{1} \mathrm{H}$ NMR spectroscopy for their free PCL- $b$-PEG/TIB-PVAL ratio (Figure 6). Both compounds were

Table 2. Dry extracts of supernatant and sediment after centrifugation of suspensions of iodinated polymer nanoparticles.

\begin{tabular}{llll} 
Reference & Before drying (g) & After drying (g) & Dry extract (\%) \\
Supernatant & 9.15 & 0.18 & 2.0 \\
Sediment & 1.51 & 0.22 & 14.6 \\
\hline
\end{tabular}

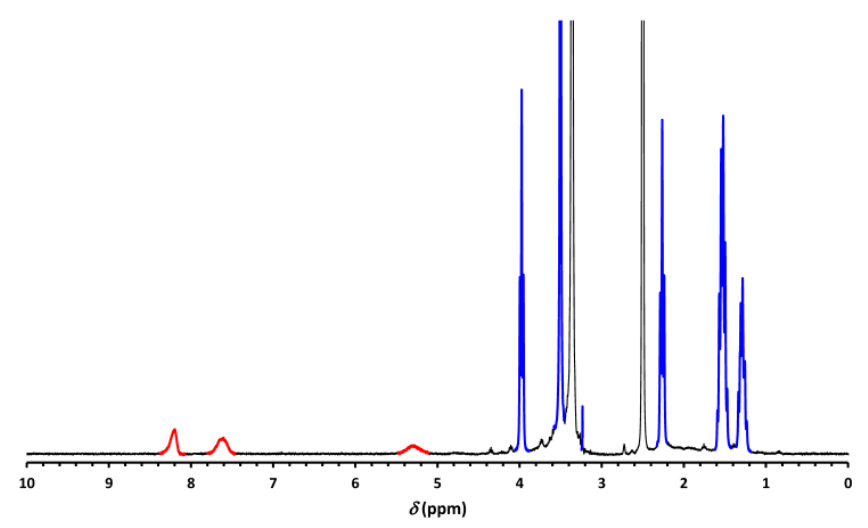

Figure 6. Reference ${ }^{1} \mathrm{H}$ NMR spectrum of $1 / 1$ PCL- $b$-PEG/TIB-PVAL mixture in DMSO-d6. Red lines are those of TIB-PVAL and blue lines are those of PCL- $b$ PEG. soluble in the DMSO- $d 6$ solvent used.

The PCL- $b$-PEG/TIB-PVAL mass ratio was calculated from the ratio $/\left(\mathrm{CH}_{2}\right)_{4 \mathrm{ppm}} / I(\mathrm{CH})_{8 \mathrm{ppm}}$ of the peak integrals of $\mathrm{CH}_{2}$ protons at $4 \mathrm{ppm}$ belonging to $\mathrm{PCL}-b$-PEG and aromatic $\mathrm{CH}$ protons at 8 ppm belonging to TIB-PVAL as:

$\frac{m(\mathrm{PCL}-b-\mathrm{PEG})}{m(\mathrm{TIB}-\mathrm{PVAL})}=\frac{\frac{I\left(\mathrm{CH}_{2}\right)_{4 \mathrm{ppm}}}{2}}{I(\mathrm{CH})_{8 \mathrm{ppm}}} \times \frac{M_{\mathrm{mol}}(\mathrm{CL})+\frac{d p(\mathrm{PEG})}{d p(\mathrm{PCL})} \times M_{\mathrm{mol}}(\mathrm{EG})}{M_{\mathrm{mol}}(\mathrm{TIB}-\mathrm{PVAL})+\frac{(1-D S)}{D S} \times M_{\mathrm{mol}}(\mathrm{VAL})}$

where $M_{\mathrm{mol}}(\mathrm{CL})=114 \mathrm{~g} \cdot \mathrm{mol}^{-1}, M_{\mathrm{mol}}(\mathrm{EG})=44 \mathrm{~g} \cdot \mathrm{mol}^{-1}, M_{\mathrm{mol}}(\mathrm{TIB}-$ $\mathrm{VAL})=526 \mathrm{~g} \cdot \mathrm{mol}^{-1}$ and $M_{\mathrm{mol}}(\mathrm{VAL})=44 \mathrm{~g} \cdot \mathrm{mol}^{-1}$ are the molar masses of caprolactone, ethylene oxide, triiodobenzoyl vinyl and vinyl alcohol repeat units respectively, $d p(\mathrm{PCL})=65$ and $d p(\mathrm{PEG})=113$ are the degrees of polymerization of the $P C L$ and PEG blocks respectively and $D S$ is the degree of substitution of TIB-PVAL.

Calculated PCL- $b$-PEG/TIB-PVAL mass ratios are given in Table 3. The mass ratio of 1 was correctly found from NMR analysis of the sample before centrifugation. No significant signal of the 2 aromatic protons specific of the iodinated polymer was found in spectra of supernatants, showing that the full TIB-PVAL was present inside nanoparticles. Finally, the chemical composition of the iodinated particles present in the sediment was obtained. In order to assess the coverage and the configuration of PEG chain at the surface, the PEG surface density expressed as the number of PEG molecules per unit area was calculated from the PCL- $b$-PEG/TIB-PVAL mass ratio. The PEG chain coverage is:

$\sigma=\frac{m(\mathrm{PCL}-b-\mathrm{PEG})}{m(\mathrm{TIB}-\mathrm{PVAL})} \times N_{\mathrm{Av}} \times \frac{\rho(\mathrm{TIB}-\mathrm{PVAL})}{M_{\mathrm{n}}(\mathrm{TIB}-\mathrm{PVAL})} \times \frac{d}{6}$

with $N_{\mathrm{Av}}=$ Avogadro constant, $\rho$ (TIB-PVAL) $=1.31 \mathrm{~g} \cdot \mathrm{cm}^{-3}$ the density of TIB-PVAL, $M_{\mathrm{n}}$ (TIB-PVAL) $=12,400 \mathrm{~g} \cdot \mathrm{mol}^{-1}$ the number-average molar mass of TIB-PVAL, and $d=150 \mathrm{~nm}$ the diameter of TIB-PVAL nanoparticles. Accordingly, the PEG chain surface density was 0.30 PEG chains per $\mathrm{nm}^{2}$ area.

The projected area of a single PEG chain end-grafted on a nanoparticle surface, also known as the PEG chain footprint was deduced: $F P=1 / \sigma=3.36 \mathrm{~nm}^{2} \cdot$ molecule $^{-1}$.

This result was compared to the cross-area of an unperturbed PEG coil in bulk water solution as calculated from the hydrodynamic radius $\left(R_{\mathrm{h}}\right)$. Based on a series of experimental measurements, Devanand and Selser ${ }^{51}$ related $R_{\mathrm{h}}$ to the PEG molar mass as a power-law relationship:

$R_{\mathrm{h}}=0.0145(\mathrm{~nm}) \times M_{\mathrm{w}}^{0.571}$

The hydrodynamic radius of an unperturbed chain of the present PEG $\left(M_{\mathrm{W}}=5000 \mathrm{~g} \cdot \mathrm{mol}^{-1}\right)$ was $1.875 \mathrm{~nm}$, giving a footprint $F P=\pi R_{\mathrm{h}}^{2}=11 \mathrm{~nm}^{2}$

Table 3. PCL- $b$-PEG/TIB-PVAL mass ratio before and after centrifugation, in supernatant and sediment of suspensions of iodinated polymer nanoparticles in water, using ${ }^{1} \mathrm{H}$ NMR spectra integrals.

\begin{tabular}{|c|c|c|}
\hline \multirow{2}{*}{ Reference } & $I\left(\mathrm{CH}_{2}\right)_{4 \mathrm{ppm}}$ & $m$ (PCL- $b-\mathrm{PEG})$ \\
\hline & $\overline{I(\mathrm{CH})_{8 \mathrm{ppm}}}$ & $\frac{m(\mathrm{IP})}{}$ \\
\hline Before centrifugation & 5.56 & 0.98 \\
\hline Supernatant & $>200$ & $>35$ \\
\hline Sediment & 1.06 & 0.19 \\
\hline
\end{tabular}




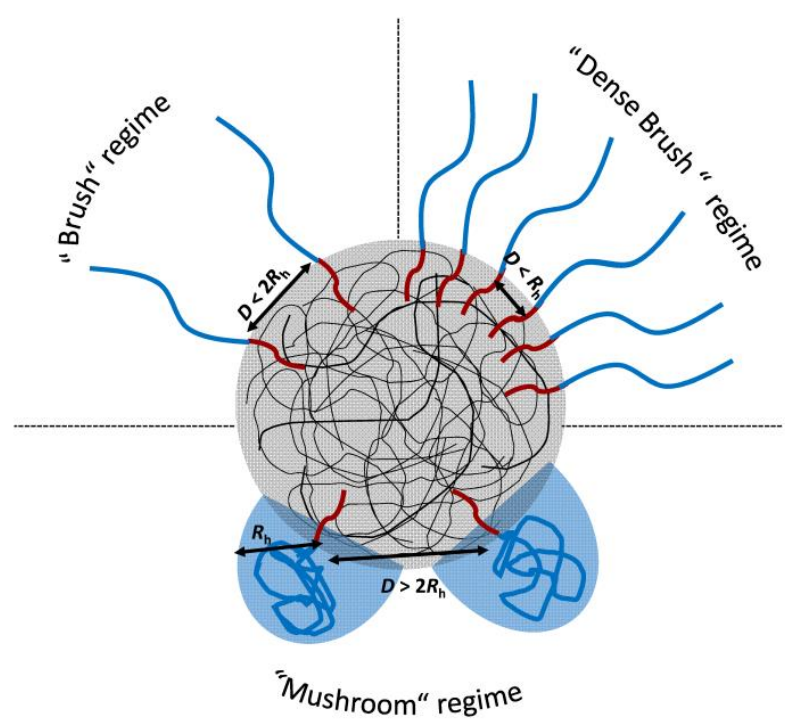

Figure 7. Various configurations of PEG chains according to the surface density. $R_{\mathrm{h}}$ : hydrodynamic radius of an unperturbed chain (minimum distance required between grafted molecules to achieve a mushroom configuration); $D$ : mean distance between anchoring points.

The experimental area $\left(F P=3.36 \mathrm{~nm}^{2} \cdot\right.$ molecule $\left.^{-1}\right)$ was much lower than that of an unperturbed coil $\left(11 \mathrm{~nm}^{2}\right)$. PEG chains were extended radially from the nanoparticles surface, which corresponded to a brush configuration ${ }^{52}$ (Figure 7). Such configuration is known to provide the best colloidal stability.

There are many reports in the literature showing the benefits of surface-tethered PEG chains in their brush regime to prevent clearance by the immune system. A rather comprehensive account is given by Perry et al. ${ }^{53}$ who investigated the successive steps of resistance against protein (opsonins) adsorption, uptake by macrophages, blood clearance, and accumulation in the liver and spleen. The surface density of crossover from mushroom to brush regime is usually estimated using the Flory radius of an unperturbed PEG chain that the exact calculation is not clear. The theoretical power-law relationship $R_{\mathrm{F}}=a N^{3 / 5}$ corresponding to a polymer coil in good solvent condition ${ }^{54}$ together with an estimate of the size of the PEG repeat unit $a=$ $0.35 \mathrm{~nm}$ that a clear bibliographic reference is never given. It looks better to rely on experimental values of hydrodynamic radius as it has been presently done. The exponent in Equation 5 is indeed close to the theoretical value of $3 / 5$; but the prefactor is smaller by a factor of $\sim 3$.

Quantitative analysis of bound PEG chains showed that a dense layer of adsorbed PEG was resisting washing of the full free PCL$b$-PEG. This is a definite benefit of block copolymers compared to classical surfactants for which bound and free molecules are in dynamic equilibrium. In this latter case removal of the free molecules causes desorption of the bound part of them in order to establish equilibrium again. The consequence is destabilization revealed by poor resistance to washing. ${ }^{32}$

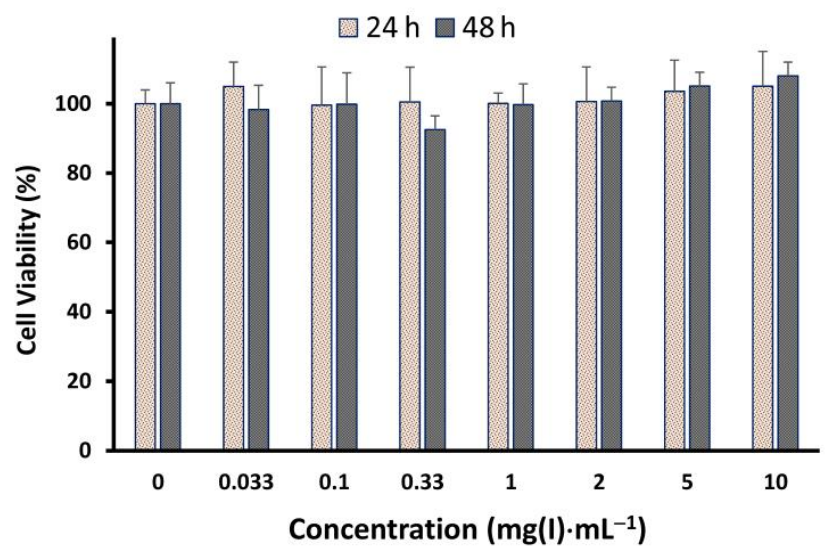

Figure 8. Cell viability by the MTS assay after $5 \mathrm{~h}$ exposure to aqueous suspensions of iodinated nanoparticles of various concentrations. Viability was assessed $24 \mathrm{~h}$ and $48 \mathrm{~h}$ after the end of exposure to nanoparticles.

\section{Cytotoxicity assessment}

Cytotoxicity of the iodinated polymer nanoparticles was determined by MTS assays performed $24 \mathrm{~h}$ and $48 \mathrm{~h}$ after incubation of macrophages with nanoparticles of different concentrations. Cell viability was calculated from the absorbance values. A standard containing pure macrophages (i.e. cells that have not been incubated with iodinated nanoparticles), was taken as the control for $100 \%$ cell viability. Full cell viability was retained after $5 \mathrm{~h}$ exposure to all suspensions of iodinated nanoparticles (Figure 8). The contrast agent does not manifest cytotoxicity in cell culture within the concentration range studied. The highest concentration was $10 \mathrm{mg}(\mathrm{l}) \cdot \mathrm{mL}^{-1}$, which was lower than the injected concentrated suspension at $100 \mathrm{mg}(\mathrm{I}) \cdot \mathrm{mL}^{-1}$. This corresponds to a concentration reached when the concentrated contrast agent is injected in the body and subsequently diluted in the plasmatic surrounding medium. A iodine concentration of $10 \mathrm{mg}(1) \cdot \mathrm{mL}^{-1}$ has a radiopacity of about $300 \mathrm{HU}$, well within the working attenuation window used in radiology. The present good biocompatibility is a definite improvement over nanoemulsions with a liquid core of iodinated oil for which the $L_{50}$ value was $0.4 \mathrm{mg} \cdot \mathrm{mL}^{-1}{ }^{29}$

All the rats stayed alive and kept in good health during the whole experiments though the injected dose was rather high.

\section{Radiopacity assessment}

\section{Radiopacity and quantification of contrast element}

$\mathrm{X}$-ray attenuation of the pure iodinated polymer was measured by taking a CT image of the polymer pressed as a pellet placed in a glass tube (Figure 9A). This picture highlights the excellent radiopaque nature of TIB-PVAL, compared to the surrounding material (wall of the glass container). The radiopacity of pure TIB-PVAL was 12,916 $\mathrm{HU}$.

Radiopacity was also assessed in vitro for phantoms made of aqueous suspensions of iodinated polymer nanoparticles at various concentrations (Figure $9 \mathrm{~B}$ and C). Radiopacity increased linearly with respect to the concentration of iodine 

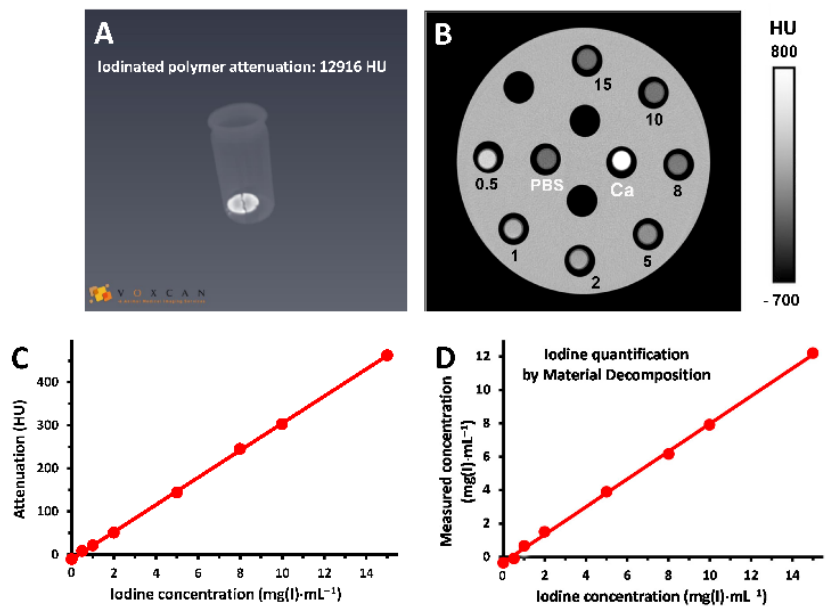

Figure 9. (A) Pellet of pressed iodinated polymer recorded with the GE BrightSpeed scanner. (B) Phantom with tubes containing the suspensions of iodinated polymer nanoparticles in water recorded with the Philips SPCCT. $\mathrm{Ca}=$ Calcium; PBS = phosphate buffer saline; numbers are iodine concentrations in $\mathrm{mg}(\mathrm{I}) \cdot \mathrm{mL}^{-1}$. (C) Graph of iodinated polymer nanoparticles attenuation in Hounsfield Units (HU) with respect to iodine concentration. (D) Quantification of iodine using material decomposition.

$\left(y=34.4 x-10.4, R^{2}=0.9998\right)$ (Figure 9C). An attenuation larger than $100 \mathrm{HU}$ required $3.5 \mathrm{mg}(\mathrm{I}) \cdot \mathrm{mL}^{-1}$. The concentration measured by SPCCT using the 'Material Decomposition' method was compared to that determined by ICP-OES in the different samples. As shown in Figure 9D, there is a good correlation between them $\left(y=0.83 x-0.315, R^{2}=0.9991\right)$. This establishes a proof of concept of the capability of SPCCT for accurate quantification of a radiopaque element in vivo. There is a systematic deviation however as the concentration inferred by Material Decomposition was lower by $83 \%$ with respect to the actual value.

\section{Discrimination of two elements in a mixture with SPCCT}

The ability of SPCCT technology to discriminate two different elements (iodine and gadolinium) has been assessed using phantoms images of mixtures of both elements. The solutions containing various concentrations of iodine and gadolinium were prepared in such way that all mixtures had the same overall attenuation in Hounsfield Units. ${ }^{8,55,56}$ Material decomposition calculation gives an iodine-specific image where the intensity of each voxel gives the concentration of iodine; $\mathrm{K}$ edge reconstruction provides the same type of information for gadolinium. ${ }^{11}$

Conventional, iodine-specific, gadolinium-specific and overlay images are shown in Figure 10. Mixed contrast agents cannot be differentiated with conventional CT. All samples of mixed contrast agents had similar attenuation of $250 \mathrm{HU}$. Contrast agents were accurately differentiated in the iodine and gadolinium specific images of SPCCT, with signal intensity proportional to their absolute concentration. Moreover, the signal of the phantom container could be subtracted, which increased the signal to background ratio, providing a potentially more accurate image for improved analysis.
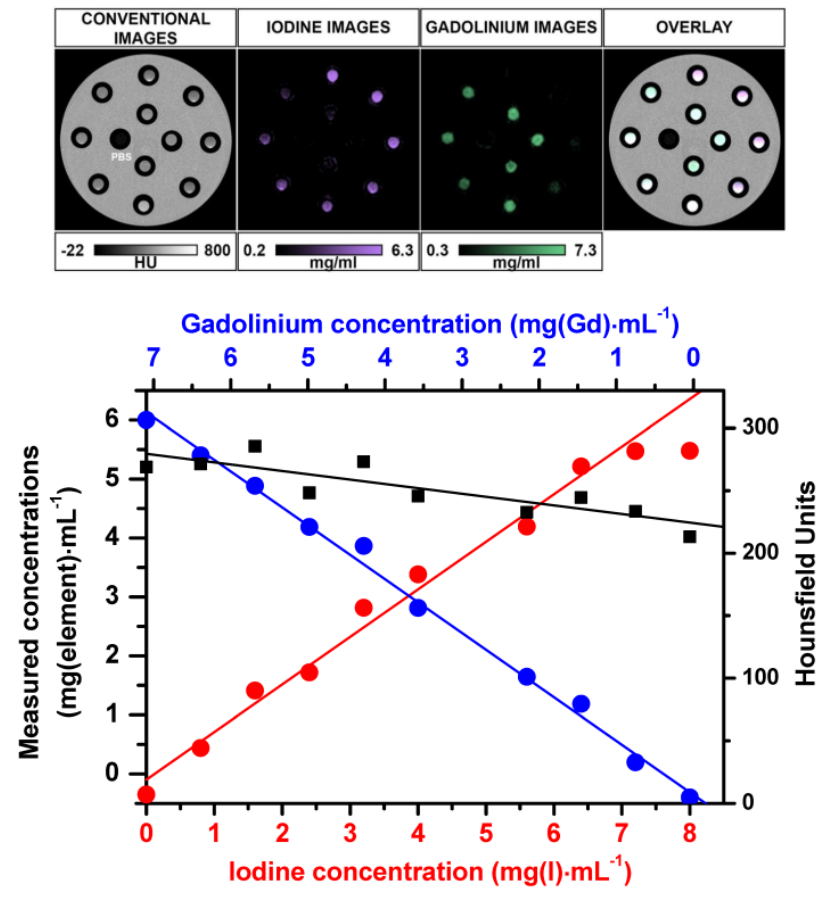

Figure 10. Top: SPCCT images of phantoms containing mixtures of iodine and gadolinium at different relative concentrations. Conventional, iodine material decomposition, gadolinium K-edge images and overlay images. Bottom: Concentrations of iodine (in red) and gadolinium (in blue) determined by Material Decomposition (iodine) and K-edge reconstruction (gadolinium), and total attenuation (HU in black) of gadolinium/iodine mixtures.

Owing to its capability to quantify and discriminate simultaneously two different elements within a single scan, the SPCCT technology is an interesting diagnostic tool for molecular imaging. For instance, it provides the possibility to image the vascular system using a blood pool agent, while targeting a specific site (i.e. atherosclerosis plaque) using a bio-conjugated contrast agent bearing another radiopaque element. Furthermore, detection and quantification of contrast agents in the region of interest within a single scan can also reduce toxicity related to the radiation dose. The need for two acquisitions in order to compare images before and postinjection becomes unavailing.

\section{The in vivo study of iodinated polymer nanoparticles}

Biodistribution of the iodinated polymer nanoparticles of $150 \mathrm{~nm}$ diameter was studied in vivo by experiments on small animals (intravenous injections to rats, according the experimental section) performed on conventional CT and $\mu \mathrm{CT}$. No visible signs of toxicity were observed post-injection. The animals remained alive and healthy during the entire study.

CT images show a radiopacity enhancement of the cardiovascular system as well as the liver and spleen after $3 \mathrm{~h}$ and up to 5 days post injection (Figure 11 left). Quantitative information is given in the graph showing the attenuation in $\mathrm{HU}$ as a function of time (Figure 11 right). Radiopacity in the abdominal aorta and the heart were quite large (200-250 HU), in the range for radiology practice. It remained at least $5 \mathrm{~h}$ 


\section{ARTICLE}
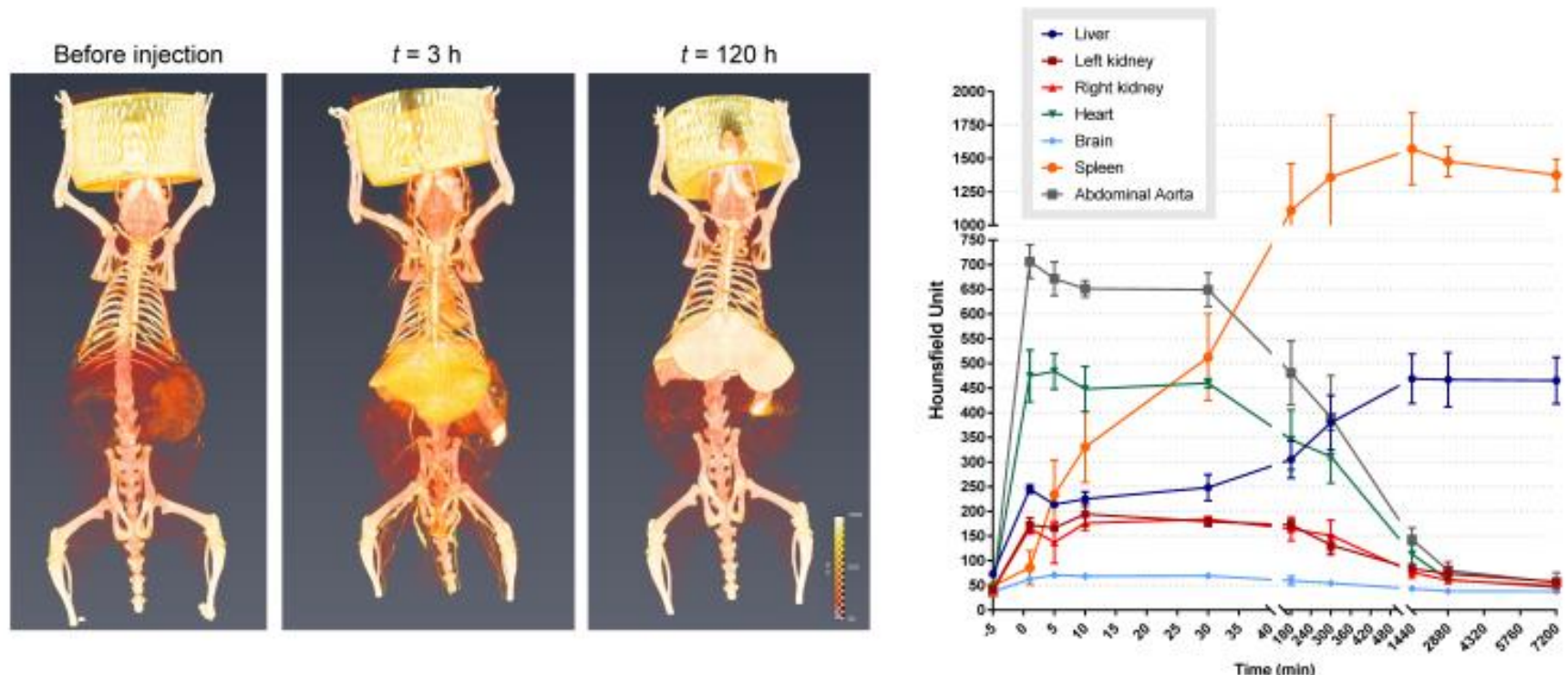

Figure 11. CT images of rats before, and $3 \mathrm{~h}, 120 \mathrm{~h}$ after IV injection $(1.5 \mathrm{~mL})$ of iodinated polymer nanoparticles (left). Biodistribution of the iodinated polymer nanoparticles over time (mean \pm sem, $n=3$ ) (right).

above $150 \mathrm{HU}$ ( 3 times the background) and went back to the initial value $(50 \mathrm{HU}) 24 \mathrm{~h}$ post administration. It also showed a slight radiopacity in the kidneys, meaning that few nanoparticles could pass through renal filters and be eliminated in urine. lodinated nanoparticles were still present in the liver $(200 \mathrm{HU})$ and the spleen $(700-750 \mathrm{HU}) 15$ days later. This indicates the potential clearance by phagocytic uptake and hepatic filtration. ${ }^{57}$ The use of nanoparticles allows imaging liver and spleen for a long time.

The biodistribution of iodinated polymer nanoparticles was compared to that of a standard solution of soluble iodinated compound (Omnipaque ${ }^{\mathrm{TM}}$ ). The CT images together with the biodistribution graph showed that the full contrast agent can be found in the kidneys $30 \mathrm{~min}$ post injection (Figure 12). Moreover 4 days later, the full have been cleared, leaving no
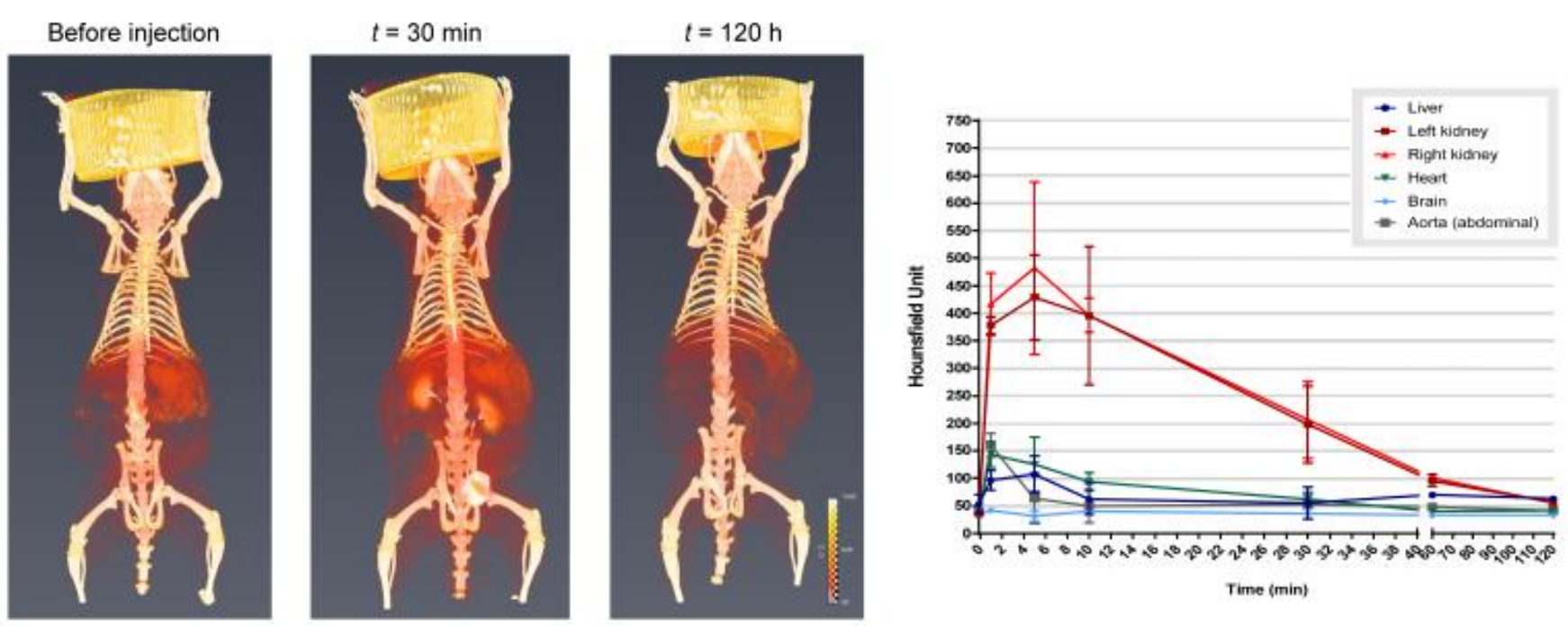

Figure 12. CT images of rats before, and $0.5 \mathrm{~h}, 120 \mathrm{~h}$ after IV injection $(0.7 \mathrm{~mL})$ of Omnipaque ${ }^{\mathrm{TM}}$ (left). CT imaging of the Omnipaque $\mathrm{e}^{\mathrm{TM}}$ biodistribution over time (mean \pm sem, $n=3$ ) (right). 


\section{ARTICLE}

trace of contrast agent inside the body. This contrast agent is suitable for a first pass angiography; it cannot be used for imaging over long durations.

$\mu C T$ images of iodinated polymer nanoparticles after IV injection confirm the observation made previously with the $C T$ scanner. $\mu \mathrm{CT}$ allowed better visualization of smaller tissues and vessels (Figure 13). In all cases, these images left no doubt as to the "blood pool" imaging characteristics of the contrast agent developed during this study.

Due to its accumulation in both the liver and spleen for prolonged time, this product is not yet suited for clinical applications. Nevertheless, it was seen that it can be used as an excellent blood pool agent as it presents biodistribution characteristics that can compete with commercially available products for preclinical studies. The difference with respect to previous similar systems is a quite long time window (several hours) for observation of vascular system. Thus, the present nanoparticles being densely coated by a PCL- $b$-PEG layer, detection by the MPS and uptake by the macrophages is very slow. Fast elimination and accumulation in the liver can be achieved by using a water-soluble surfactant instead of the PCL$b$-PEG block copolymer as a stabilizer. This has been achieved with MAOTIB nanoparticles stabilized by a nonionic surfactant. ${ }^{32}$
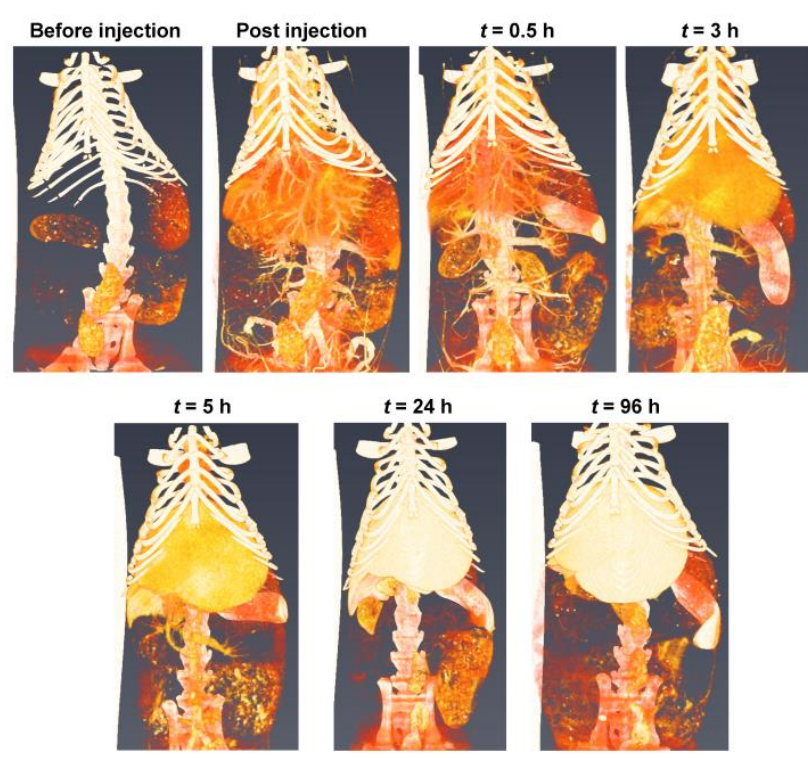

Figure 13. $\mu \mathrm{CT}$ images after intravenous injection into a rats' tail vein of $1.5 \mathrm{~mL}$ of aqueous dispersion of iodinated polymer nanoparticles (90$\left.100 \mathrm{mg}(\mathrm{I}) \cdot \mathrm{mL}^{-1}\right)$. Images were acquired before and at different time points after injection.

\section{Experimental}

\section{Materials}

\section{Chemicals}

The following analytical-grade chemicals were purchased and used without further purification: 2,3,5-triiodobenzoic acid (Changzhou Ilhang Fine Chemical Co. Ltd, China), thionyl chloride (Acros Organics, 99.5\%), sodium carbonate, dichloromethane (Acros Organics, 99.9\%). N-methyl-2pyrrolidone (NMP, 99.5\%), pyridine (99.5\%) and 4dimethylaminopyridine (DMAP, 99.5\%) were purchased from Acros Organics in anhydrous grade over molecular sieves in an AcroSeal packaging. Poly(vinyl alcohol) (PVAL, Sigma-Aldrich, 98\% hydrolyzed, average molar mass $M_{\mathrm{W}}=13,000-23,000 \mathrm{Da}$ ) was dried at $40{ }^{\circ} \mathrm{C}$ in an oven for $24 \mathrm{~h}$ under vacuum before use. Tetrahydrofuran (THF, Fisher Scientific), absolute anhydrous ethanol (Carlo Erba) were used in purification processes. The polycaprolactone-block-poly(ethylene glycol) (PCL- $b$-PEG block copolymer) was synthesized by polymerization of caprolactone initiated by poly(ethylene glycol) monomethyl ether catalyzed by tin octanoate as reported in refs ${ }^{58,59}$ The degrees of polymerization of the poly(caprolactone) and. poly(ethylene glycol) blocks were 65 and 113 respectively $\left(\mathrm{PCL}_{65}-b-\mathrm{PEG}_{113}\right)$. Deionized water of $18 \Omega \cdot \mathrm{cm}$ resistivity was used for all preparations.

\section{Cells}

The BALB/c mice peritoneal macrophage cell line J774A.1 from the European Collection of Cell Cultures (ECACC, 91051511) was used to assess cytotoxicity. These cells were maintained at $37{ }^{\circ} \mathrm{C}$ with $5 \% \mathrm{CO}_{2}$ by successive passages in RPMI-1640 culture medium (PAA Laboratories, GE Healthcare, Pasching, Austria) containing $10 \%(\mathrm{v} / \mathrm{v})$ fetal bovine serum (from Sigma, StQuentin Fallavier, France), $1 \%$ MycoKill $A B$ and $1.5 \%$ penicillin/streptomycin.

\section{Animals}

All experimental procedures involving animals and their care were carried out in accordance with the European regulation for animal use (APAFIS agreement number \#00841.01). Wistar rats (male, body weight 200-300 g) from Janvier Labs (Le GenestSaint-Isle, France) were used for the in vivo studies. The animals were maintained in standard cages at $20-25^{\circ} \mathrm{C}$ with humidity $>$ $35 \%$. The lighting cycle was the following: $12 \mathrm{~h}$ of artificial lighting/ $12 \mathrm{~h}$ of darkness. Water and standard laboratory food were given ad libitum. The rats were sedated before imaging using a mix of isoflurane (1-5\%) and oxygen as a carrier gas in order to maintain general anesthesia throughout the duration 
of the study. A catheter was placed in the tail vein for administration of contrast agent.

\section{Synthesis of the iodinated polymer (TIB-PVAL)}

TIB-PVAL was prepared by an esterification reaction of 2,3,5triiodobenzoyl chloride (TIBCI) and the alcohol groups of PVAL according to the reaction scheme shown in Figure 14.

Synthesis of 2,3,5-triiodobenzoyl chloride (TIBCI). $100.53 \mathrm{~g}$ ( $0.20 \mathrm{~mol})$ of 2,3,5-triiodobenzoic acid was suspended in $180 \mathrm{~mL}$ (1.56 mol, $7.8 \mathrm{eq}$ ) of thionyl chloride in a $500 \mathrm{~mL}$ round bottomed flask fitted with a condenser. The suspension was refluxed under stirring until hydrochloric acid release ceased. After cooling, thionyl chloride was removed under reduced pressure with $\mathrm{Na}_{2} \mathrm{CO}_{3}$ into the receptor flash to trap acidic vapors $\left(\mathrm{HCl}, \mathrm{SOCl}_{2}\right)$. Recrystallization of the brown solid from dichloromethane $(80 \mathrm{~mL}, 3$ days at room temperature for crystal growth) yielded $\mathrm{TIBCl}$ as large light brown prisms (67.3 g, yield $=65 \%)$.

${ }^{1} \mathrm{H}$ NMR (300 MHz, $\mathrm{CDCl}_{3}, \delta$ in ppm from TMS): 7.89 (d, $3 J_{\mathrm{H}-\mathrm{H}}=$ $1.9 \mathrm{~Hz}, 1 \mathrm{H}$, arom- $\left.\mathrm{H}_{\text {para }}\right), 8.37\left(\mathrm{~d}, 3^{3} \mathrm{H}-\mathrm{H}=1.9 \mathrm{~Hz}, 1 \mathrm{H}\right.$, arom- $\left.\mathrm{H}_{\text {ortho }}\right)$.

Synthesis of the iodinated polymer (TIB-PVAL). The radiopaque polymer was prepared by binding the TIBCI iodinated molecule to poly(vinyl alcohol) (Figure 14) as described in the literature. ${ }^{42,60}$ Solution $A$ was prepared in a round-bottom flask by dissolving $117.64 \mathrm{~g}(0.227 \mathrm{~mol}, 1 \mathrm{eq})$ of $\mathrm{TIBCl}$ in extra dry NMP $(60 \mathrm{~mL})$. Solution $B$ was prepared in a three-neck roundbottom flask: PVAL (10 g, $1 \mathrm{eq}), 3.33 \mathrm{~g}$ of DMAP $(0.027 \mathrm{~mol}$, $0.12 \mathrm{eq})$ and NMP $(300 \mathrm{~mL})$ were stirred for $20 \mathrm{~min}$ at $130{ }^{\circ} \mathrm{C}$ under dry nitrogen gas flow until the polymer was dissolved to completion. The solution was then cooled down to room temperature, and $21.53 \mathrm{~g}$ of pyridine $(0.272 \mathrm{~mol}, 1.2 \mathrm{eq})$ was added. Solution $A$ was poured dropwise into solution $B$ and the

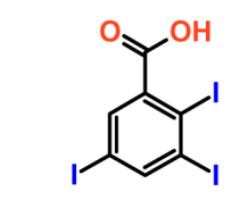

2,3,5-triiodobenzoic acid (TIBA)

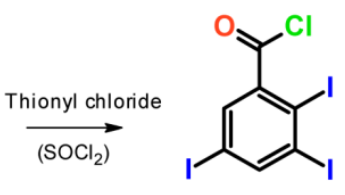

2,3,5-triiodobenzoyl chlorid (TIBCl)

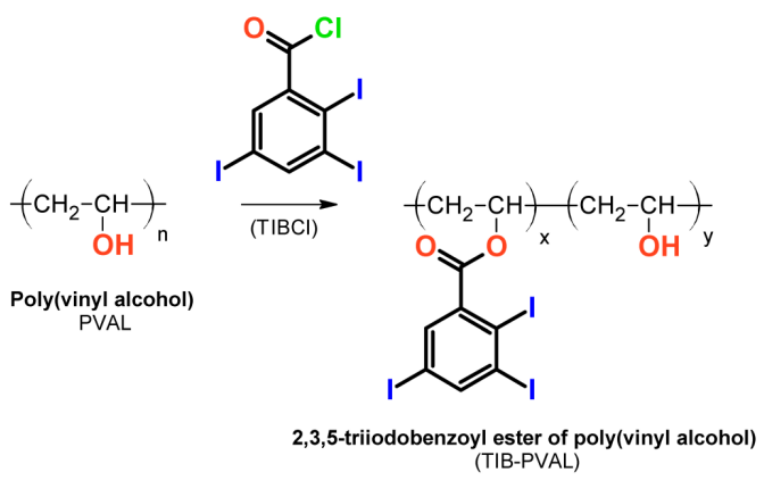

Figure 14. Synthesis of iodinated polymer (TIB-PVAL): synthesis of 2,3,5triiodobenzoyl chloride (top), covalent linkage of 2,3,5-triiodobenzoyl chloride to poly(vinyl alcohol) (bottom).

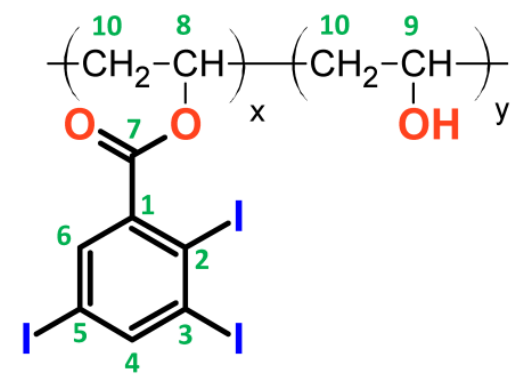

Figure 15. ${ }^{13} \mathrm{C}$ NMR assignment of TIB-PVAL.

mixture was heated at $60^{\circ} \mathrm{C}$ under magnetic stirring overnight under inert atmosphere. TIB-PVAL was recovered by precipitation from the reaction medium in $1 \mathrm{~L}$ of deionized water, filtration and drying in a vacuum oven at $40{ }^{\circ} \mathrm{C}$. The dry product was purified by dissolution in a minimum amount of THF and precipitation in a large volume of ethanol under strong magnetic stirring. After filtration, TIB-PVAL was dried in an oven at $40{ }^{\circ} \mathrm{C}$ under vacuum. Such precipitation process was repeated until the sharp lines of organic solvents (NMP and ethanol) and $\mathrm{TIBCl}$ were no longer detected in the ${ }^{1} \mathrm{H} N M R$ spectrum. Finally, a beige powder was recovered $(78 \mathrm{~g}$, yield $=$ $61 \%)$.

${ }^{1} \mathrm{H}$ NMR (300 MHz, DMSO- $d 6, \delta$ in ppm from TMS): 1.35-2.0 (m, $\mathrm{CH} 2$ PVAL chain, $2(\mathrm{x}+\mathrm{y})), 3.78$ (s, $\mathrm{CH}-\mathrm{OH}$ PVAL chain, $\mathrm{y})$, 3.98-4.95 (m, OH), 5.30 (s, CH-OTIB PVAL chain, $x$ ), 7.63 (broad unresolved doublet, arom- $\left.H_{\text {para }}, x\right), 8.22$ (broad unresolved doublet, arom- $\left.\mathrm{H}_{\text {ortho }}, x\right)$.

${ }^{13} \mathrm{C}$ NMR (126 MHz, DMSO- $d 6$, $\delta$ in ppm from TMS); assignments are given in Figure 15: $165.18 C_{7}, 148.24 C_{4}, 139.60 C_{1}, 136.22$ $C_{6}, 114.89 C_{3}, 107.25 C_{2}, 95.37 C_{5}, 69.85 C_{8}, 63.67 C_{9}, 41.84 C_{10}$. IR $\left(\mathrm{cm}^{-1}\right)$ : 3360 (broad band of associated O-H), $2916.2(\mathrm{C}-\mathrm{H})$, 1721.6 ( $\mathrm{C}=\mathrm{O}$ of ester), 1519.0 ( $\mathrm{C}-\mathrm{H}$ aromatic), 1362.1 ( $\mathrm{C}-\mathrm{OH})$, 1259.3 (aromatic ester), 1175.9 (C-H aromatic), 1097.0 (aromatic ester), 999.1 (C-H aromatic).

\section{Preparation of nanoparticles}

Nanoparticles (NPs) of iodinated polymer were prepared using the nanoprecipitation process. ${ }^{41,61}$ TIB-PVAL $(1 \mathrm{~g})$ and the PCL$b$-PEG dispersing agent $(1 \mathrm{~g})$ were dissolved together in $25 \mathrm{~mL}$ of THF. The weight ratio iodinated polymer/dispersing agent was set to $1 / 1$. The organic solution was added dropwise to $50 \mathrm{~mL}$ of water under magnetic stirring using a syringe fitted with a needle $21 \mathrm{G}(0.8 \mathrm{~mm}$ internal diameter). Note that the organic solvent/water volume ratio of $1 / 2$ has been described in the literature as optimum to obtain suitable particle size in the nanoparticle range. ${ }^{43,62}$ Finally, THF was evaporated under reduced pressure, yielding an aqueous suspension of nanoparticles. The iodine concentration of the dispersion was $17 \mathrm{mg}(\mathrm{I}) \cdot \mathrm{mL}^{-1}$ (ICP-OES). A sketch of the full process is given in Figure 16.

A concentration step has been implemented after the initial nanoprecipitation step that yielded suspensions of too low concentrations. An aliquot $(10 \mathrm{~mL})$ of the dispersion prepared by nanoprecipitation was centrifuged (7,930 rpm, $20 \mathrm{~min}$ ), the 


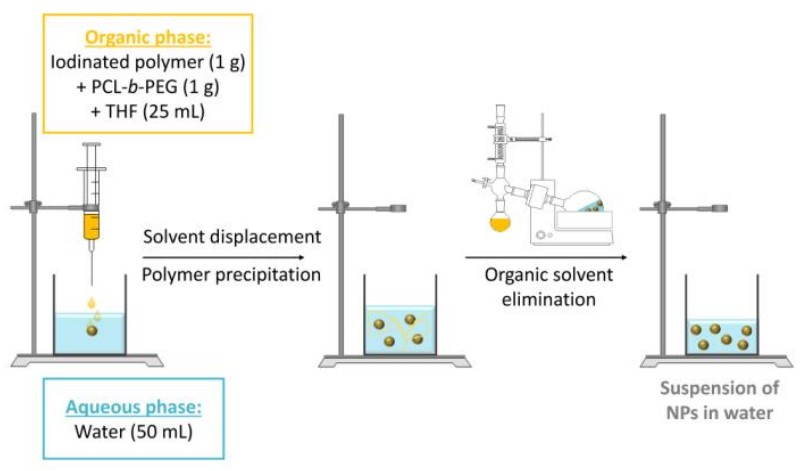

Figure 16. The nanoprecipitation process.

supernatant was removed, and the sediment was redispersed in a minimum amount of water ( $1 \mathrm{~mL})$, using an ultrasound bath at $40{ }^{\circ} \mathrm{C}(2 \mathrm{~h})$. The iodine concentration was $98.8 \mathrm{mg}(\mathrm{I}) \cdot \mathrm{mL}^{-1}$ (ICP-OES) after the concentration step and the same particle size was kept.

\section{Methods}

\section{Characterization of the iodinated polymer}

The grafting reaction of the TIBCl onto PVAL was monitored by ${ }^{1} \mathrm{H}$ NMR. Spectra of the TIB-PVAL solutions in deuterated dimethylsulfoxide (DMSO-d6) were recorded on Bruker ALS300 and DRX300 Fourier transform spectrometers (300 MHz). Data processing was done using MestrecNova (Mnova) software. The degree of substitution, $D S=x /(x+1)$, was calculated by comparing the area under the peaks corresponding to the aromatic protons to the area under the peaks corresponding to the $\mathrm{CH}_{2}$ of the PVAL backbone at 1.3-2.0 ppm.

IR spectra were recorded in ATR mode using a Thermo Scientific iS50 FTIR spectrometer equipped with an iS50 ATR module. A small amount of fine powder of compound was deposited on the diamond crystal of the ATR equipment, and the spectrum was recorded between 400 and $4000 \mathrm{~cm}^{-1}$ by accumulation of 32 scans at $2 \mathrm{~cm}^{-1}$ resolution.

UV absorbance of solutions was measured in Hellma Quartz cells of $1 \mathrm{~mm}$ thickness using a Varian Cary 50 spectrometer. The absorbance of the solvent (THF) was subtracted as a background.

The amount of iodine was determined by ICP-OES measurements on the polymer in solution using a Vista-Pro CCD simultaneous ICP-OES Varian instrument at the Institut des Sciences Analytiques (University of Lyon 1). The iodinated polymer was mineralized in $\mathrm{HNO}_{3}$ for $24 \mathrm{~h}$ and the solution was subsequently diluted with water down to $0.2 \mathrm{ppm}$ such that the concentration of iodine was in the working range of ICP-OES. The mass fraction of iodine calculated from the $D S$ determined from ${ }^{1} \mathrm{H}$ NMR analysis was compared to that measured by ICP. OES

A Thermogravimetric Analysis (TGA) instrument Netzsch TG 209 F1 was used for recording the mass loss of samples held in an alumina crucible under dry nitrogen flow between $20^{\circ} \mathrm{C}$ and $1000^{\circ} \mathrm{C}$ at a heating rate of $10^{\circ} \mathrm{C} \cdot \mathrm{min}^{-1}$.
A Differential Scanning Calorimetry (DSC) Q200 TA instrument was used for measurement of thermal transitions of the iodinated polymer. The amorphous/crystalline character of the polymer was evaluated by looking for characteristic thermal events such as glass transition $\left(T_{\mathrm{g}}\right)$, melting, and crystallization on cooling.

X-ray crystallography was performed using a Bruker D8 Advance diffractometer at the Centre de Diffractométrie Henri Longchambon of the University Lyon 1 (http://cdalpha.univIyon1.fr/). The purpose was to determine whether there were crystalline parts in the polymer.

\section{Characterization of iodinated polymer nanoparticles}

The hydrodynamic diameter and size distribution of nanoparticles dispersed in aqueous medium were determined using Dynamic Light Scattering (DLS) using a Zetasizer Nano ZS instrument from Malvern Panalytical. This technique is sensitive to particles of size in a $10-2000 \mathrm{~nm}$ diameter range and for diluted suspensions (ideal count rate $100-350 \mathrm{kHz}$ ). Two approaches can be used: the cumulant fit provides a $z$-average and a polydispersity index $(P d l)$, and the inverse Laplace transform of the autocorrelation function by the CONTIN method provides the nanoparticle size distribution in scattered intensity, particle number or volume. Both calculation methods gave very close results. For the sake of comparison with other publications, the cumulant fit will be used to discuss on DLS results. They will be compared with size distribution in number measured by Transmission Electron Microscopy (TEM). Nanoparticle stability in water and in human serum at $4{ }^{\circ} \mathrm{C}$, $20^{\circ} \mathrm{C}$ and $37^{\circ} \mathrm{C}$, was checked by measuring the hydrodynamic diameter over time.

Transmission Electron Microscopy (TEM) pictures were obtained with a Philips CM120 electron microscope under $80 \mathrm{kV}$ accelerating voltage, at the Centre Technologique des Microstructures (CT $\mu)$ University of Lyon 1 (http://microscopies.univ-lyon1.fr/). Samples were prepared by deposition of a drop $(5 \mu \mathrm{L})$ of diluted formulation on a 400 -mesh carbon-coated copper grid and drying in open air. The size distribution and average size of dry particles was determined from diameters of more than 100 particles determined by image analysis using the ImageJ software.

PEG density on the nanoparticle surface was calculated using dry extract measurement (oven at $40{ }^{\circ} \mathrm{C}$ under vacuum) and ${ }^{1} \mathrm{H}$ NMR analysis. The projected area per PEG chain, also known as PEG chain footprint was deduced and compared to that of unperturbed PEG coil in bulk water.

For cytotoxicity assessment, J774A.1 cells were cultured in a 96 wells plate. Once cells had developed a monolayer, they were incubated with iodinated polymer nanoparticles at concentrations of iodine of $0 \mathrm{mg}(\mathrm{I}) \cdot \mathrm{mL}^{-1}, \quad 5 \mathrm{mg}(\mathrm{I}) \cdot \mathrm{mL}^{-1}$, $2 \mathrm{mg}(\mathrm{I}) \cdot \mathrm{mL}^{-1}, 1 \mathrm{mg}(\mathrm{I}) \cdot \mathrm{mL}^{-1}, 0.33 \mathrm{mg}(\mathrm{I}) \cdot \mathrm{mL}^{-1}, 0.1 \mathrm{mg}(\mathrm{I}) \cdot \mathrm{mL}^{-1}$ and $0.033 \mathrm{mg}(\mathrm{l}) \cdot \mathrm{mL}^{-1}$ for $5 \mathrm{~h}$ before the culture medium was replaced by a new cell culture medium free of iodinated nanoparticles. Cell viability was determined after $24 \mathrm{~h}$ and $48 \mathrm{~h}$ using a MTS/PMS solution (CellTiter 96; Aqueous Nonradioactive cell Proliferation Assay, Promega, Madison, WI, USA). The absorbance of the formazan product was measured 
at $490 \mathrm{~nm}$ with a plate reader (Thermo Fisher Scientific 51118177 Multiskan EX Microplate Photometer, Villebon-surYvette, France).

\section{CT imaging}

Three types of $\mathrm{CT}$ instruments were used:

A General Electric (GE) BrightSpeed scanner equipped with an $\mathrm{X}$-ray tube operating at $120 \mathrm{kV}$ voltage, $100 \mathrm{~mA}$ tube current and the Avizo Fire reconstruction software provided multi-layer pictures of $310 \mu \mathrm{m}$ spatial resolution.

A Bruker SkyScan 1278 micro CT ( $\mu \mathrm{CT}$ ) equipped with an X-ray tube operating at $57 \mathrm{kV}$ voltage, $753 \mu \mathrm{A}$ tube current was used for imaging animals at higher spatial resolution of $51.7 \mu \mathrm{m}$.

A modified clinical base small FOV prototype Spectral Photon Counting Computed Tomography instrument (SPCCT, Philips Healthcare, Haifa, Israel) was also used to assess radiopacity. SPCCT acquisitions were performed at $100 \mathrm{~mA}$ tube current and $120 \mathrm{kVp}$ tube voltage.

In vitro radiopacity of phantoms made of both the modified polymer in pellet and the aqueous suspensions was measured from CT scans. Pellets were prepared by pressing $20 \mathrm{mg}$ of the dry iodinated polymer powder using a $13 \mathrm{~mm}$ Die Kit Pike technologies press at $7.4 \times 10^{8} \mathrm{~Pa}$ pressure. Aqueous suspensions at different concentrations were contained in $1.5 \mathrm{~mL}$ Eppendorf tubes. Phantoms of two contrast elements were imaged and compared: nanoparticles of iodinated polymer and standard commercially available solution of gadolinium (ProHance/Gadoteridol, Bracco). Appropriate energy thresholds were chosen to provide optimal discrimination of gadolinium and iodine. The attenuation was measured in Hounsfield Units (HU) and elements concentrations were determined using specific reconstruction algorithms: Material Decomposition (MD) for iodine and K-edge reconstruction for gadolinium.

In vivo CT imaging of rat models (male, 250-300 g) allowed to evaluate radiopacity and assess biodistribution of the contrast agent in vivo. A volume of $1.5 \mathrm{~mL}$ of aqueous suspensions of iodinated polymer nanoparticles of concentration 90$100 \mathrm{mg}(\mathrm{I}) \cdot \mathrm{mL}^{-1}$ were intravenously administrated into the tail vein. This corresponded to a dose per animal weight of $500-600 \mathrm{mg}(\mathrm{I}) \cdot \mathrm{kg}^{-1}$. Biodistribution of iodinated polymer nanoparticles was compared to that of a commercial solution of small iodinated molecules $\left(0.7 \mathrm{~mL}\right.$ of Omnipaque ${ }^{\mathrm{TM}}$ $350 \mathrm{mg}(\mathrm{I}) \cdot \mathrm{mL}^{-1}$, Bracco). Full body $\mathrm{CT}$ and $\mu \mathrm{CT}$ scans were performed before injection, and from $5 \mathrm{~min}$ up to 15 days after injection at different time points.

\section{Conclusions}

Concentrated dispersions of iodinated polymer nanoparticles formed by nanoprecipitation of a triiodobenzoyl moiety covalently grafted to poly(vinyl alcohol) have been prepared. These nanoparticles are composed of a fully amorphous core that might be used for encapsulation of hydrophobic drugs, thus creating a theranostic compound. A PEGylated shell brought by the PCL- $b$-PEG dispersing agent, in dense brush conformation, provides steric stabilization up to 8 months in water and human serum and stealth properties against immune system when circulating in blood. This caused a slow uptake into spleen and liver. An optimal formulation, composed of monodisperse nanoparticle core size of around $150 \mathrm{~nm}$ (TEM average diameter) and concentrated up to $100 \mathrm{mg}(\mathrm{l}) \cdot \mathrm{mL}^{-1}$, was evaluated for radiopacity in vitro and in vivo. The high potential of the SPCCT technology in multicolor molecular imaging for improved diagnosis has been demonstrated in phantoms. The iodinated polymer nanoparticles provided significant radiopacity of the cardiovascular system for several hours, and can be used for imaging the liver and the spleen. Therefore, the present contrast agents are useful both as blood pool agent for angiography over long durations without multiple injections and as passive targeting agents in organs from the mononuclear phagocyte system (liver and spleen) and more generally in tissues/pathologies with damaged vasculature (i.e. cancer, aneurysm, internal bleeding ...).

\section{Conflicts of interest}

There are no conflicts to declare.

\section{Acknowledgements}

The research project has received funding from European Union through Horizon 2020 research and innovation program under grant agreement No 643694.

\section{References}

1 D.P. Cormode, E. Roessl, A. Thran, T. Skajaa, R.E. Gordon, J.-P. Schlomka, V. Fuster, E.A. Fisher, W.J.M. Mulder, R. Proksa and Z.A. Fayad, Atherosclerotic plaque composition: analysis with multicolor CT and targeted gold nanoparticles, Radiology 2010, 256, 774-782.

2 D. Pan, E. Roessl, J.-P. Schlomka, S.D. Caruthers, A. Senpan, M.J. Scott, J.S. Allen, H. Zhang, G. Hu, P.J. Gaffney, E.T. Choi, V. Rasche, S.A. Wickline, R. Proksa and G.M. Lanza, Angew. Chem. Int. Ed. 2010, 49, 9635-9639.

3 S. Si-Mohamed, D. Bar-Ness, M. Sigovan, D.P. Cormode, P. Coulon, E. Coche, A. Vlassenbroek, G. Normand, L. Boussel and P. Douek, Nucl. Instr. Methods Phys. Res. Section A: Accelerators, Spectrometers, Detectors and Associated Equipment 2017, 873, 27-35.

4 D.P. Cormode and Z.A. Fayad, Imaging Med. 2011, 3, 263266.

5 A. de Vries, E. Roessl, E. Kneepkens, A. Thran, B. Brendel, G. Martens, R. Proska, K. Nicolay and H. Grüll, Invest. Radiol. 2015, 50, 297-304.

6 D.P. Cormode, S. Si-Mohamed, D. Bar-Ness, M. Sigovan, P.C. Naha, J. Balegamire, F. Lavenne, P. Coulon, E. Roessl, M. Bartels, M. Rokni, I. Blevis, L. Boussel and P. Douek, Sci. Rep. 2017, 7, 4784.

7 D. Muenzel, D. Bar-Ness, E. Roessl, I. Blevis, M. Bartels, A.A. Fingerle, S. Ruschke, P. Coulon, H. Daerr, F.K. Kopp, B. Brendel, A. Thran, M. Rokni, J. Herzen, L. Boussel, F. Pfeiffer, R. Proksa, E.J. Rummeny, P. Douek and P.B. Noël, Radiology 2017, 283, 723-728.

8 J. Dangelmaier, D. Bar-Ness, H. Daerr, D. Muenzel, S. SiMohamed, S. Ehn, A.A. Fingerle, M.A. Kimm, F.K. Kopp, L. 
Boussel, E. Roessl, F. Pfeiffer, E.J. Rummeny, R. Proksa, P. Douek and P.B. Noël, Eur. Radiol. 2018, 28, 3318-3325.

9 S. Si-Mohamed, A. Thivolet, P.-E. Bonnot, D. Bar-Ness, V. Képénékian, D.P. Cormode, P. Douek and P. Rousset, Invest. Radiol. 2018, 53, 629-639.

10 E. Roessl and R. Proksa, Phys. Med. Biol. 2007, 52, 4679-4696.

11 J.P. Schlomka, E. Roessl, R. Dorscheid, S. Dill, G. Martens, T. Istel, C. Bäumer, C. Herrmann, R. Steadman, G. Zeitler, A. Livne and R. Proksa, Phys. Med. Biol. 2008, 53, 4031-4047.

12 S. Si-Mohamed, D.P. Cormode, D. Bar-Ness, M. Sigovan, P.C. Naha, J.-B. Langlois, L. Chalabreysse, P. Coulon, I. Blevis, E. Roessl, K. Erhard, L. Boussel and P. Douek, Nanoscale 2017, 9 18246-18257.

13 C.O. Schirra, B. Brendel, M.A. Anastasio and E. Roessl, Contrast Media Mol. Imaging 2014, 9, 62-70.

14 E. Seeliger, M. Sendeski, C.S. Rihal and P.B. Persson, Eur. Heart. J. 2012, 33, 2007-2015.

15 D.P. Cormode, T. Skajaa, Z.A. Fayad and W.J.M. Mulder, Arterioscler. Thromb. Vasc. Biol. 2009, 29, 992-1000.

16 A. Jakhmola, N. Anton and T.F. Vandamme, Adv. Healthcare Mater. 2012, 1, 413-431.

17 M. Shilo, T. Reuveni, M. Motiei and R. Popovtzer, Nanomedicine 2012, 7, 257-269.

18 M. Longmire, P.L. Choyke and H. Kobayashi, Nanomedicine 2008, 3, 703-717.

19 Y.C. Dong, M. Hajfathalian, P.S.N. Maidment, J.C. Hsu, P.C. Naha, S. Si-Mohamed, M. Breuilly, J. Kim, P. Chhour, P. Douek, H.I. Litt and D.P. Cormode, Sci. Rep. 2019, 9, 14912.

20 J. Kim, D. Bar-Ness, S. Si-Mohamed, P. Coulon, I. Blevis, P. Douek and D.P. Cormode, Sci. Rep. 2018, 8, 12119.

21 A.T. Yordanov, A.L. Lodder, E.K. Woller, M.J. Cloninger, N. Patronas, D. Milenic and M.W. Brechbiel, Nano Lett. 2002, 2 595-599.

22 Y. Fu, D.E. Nitecki, D. Maltby, G.H. Simon, K. Berejnoi, H.-J. Raatschen, B.M. Yeh, D.M. Shames and R.C. Brasch, Bioconjugate Chem. 2006, 17, 1043-1056.

23 S. Mukundan, K.B. Ghaghada, C.T. Badea, C.-Y. Kao, L.W. Hedlund, J.M. Provenzale, G.A. Johnson, E. Chen, R.V Bellamkonda and A. Annapragada, AJR Am. J. Roentgenol. 2006, 186, 300-307.

24 V.P. Torchilin, M.D. Frank-Kamenetsky and G.L. Wolf, Acad. Radiol. 1999, 6, 61-65.

25 Y. Zou, Y. Wei, G. Wang, F. Meng, M. Gao, G. Storm and Z. Zhong, Adv. Mater. 2017, 29, 1603997.

26 Y. Zou, Y. Wei, Y. Sun, J. Bao, F. Yao, F. Meng, C. Hu, G. Storm and Z. Zhong, Theranostics 2019, 9, 8061-8072.

27 A. de Vries, E. Custers, J. Lub, S. van den Bosch, K. Nicolay and H. Grüll, Biomaterials 2010, 31, 6537-6544.

28 X. Li, N. Anton, G. Zuber, M. Zhao, N. Messaddeq, F. Hallouard, H. Fessi and T.F. Vandamme, Biomaterials 2013, 34, 481-491.

29 M.F. Attia, N. Anton, M. Chiper, R. Akasov, H. Anton, N. Messaddeq, S. Fournel, A.S. Klymchenko, Y. Mély and T.F. Vandamme, ACS Nano 2014, 8, 10537-10550.

30 F. Hyafil, J.-C. Cornily, J.E. Feig, R. Gordon, E. Vucic, V. Amirbekian, E.A. Fisher, V. Fuster, L.J. Feldman and Z.A. Fayad, Nature Med. 2007, 13, 636-641.

31 Q. Yin, F.Y. Yap, L. Yin, L. Ma, Q. Zhou, L.W. Dobrucki, T.M. Fan, R.C. Gaba and J. Cheng, J. Am. Chem. Soc. 2013, 135, 13620-13623.

32 J. Wallyn, N. Anton, C.A. Serra, M. Bouquey, M. Collot, H. Anton, J.-L. Weickert, N. Messaddeq and T.F. Vandamme, Acta Biomater. 2018, 66, 200-212.

33 F. Hallouard, N. Anton, P. Choquet, A. Constantinesco and T. Vandamme, Biomaterials 2010, 31, 6249-6268.

34 X. Li, N. Anton, G. Zuber and T. Vandamme, Adv. Drug Deliv. Rev. 2014, 76, 116-133.

35 H. Lusic and M.W. Grinstaff, Chem. Rev. 2013, 113, 1641-1666.
36 C. Chauvierre, D. Labarre, P. Couvreur and C. Vauthier, Macromolecules 2003, 36, 6018-6027.

37 A. Galperin, D. Margel, J. Baniel, G. Dank, H. Biton and S. Margel, Biomaterials 2007, 28, 4461-4468.

38 A.J. Paine, W. Luymes and J. McNulty, Macromolecules 1990 23, 3104-3109.

39 Y.S. Leong and F. Candau, J. Phys. Chem. 1982, 86, 2269-2271.

40 S.K. Karode, S.S. Kulkarni, A.K. Suresh and R.A. Mashelkar, Chem. Eng. Sci. 1998, 53, 2649-2663.

$41 \mathrm{H}$. Fessi, F. Puisieux, J.P. Devissaguet, N. Ammoury and S. Benita, Int. J. Pharm. 1989, 55, R1-R4.

42 F. Mottu, D.A. Rüfenacht, A. Laurent and E. Doelker, Biomaterials 2002, 23, 121-131.

43 C. Fonseca, S. Simes and R. Gaspar, J. Control. Release 2002 83, 273-286.

44 F. Lince, D.L. Marchisio and A.A. Barresi, J. Colloid Interface Sci. 2008, 322, 505-515.

45 B.J. Nehilla, M. Bergkvist, K.C. Popat and T.A. Desai, Int. J. Pharm. 2008, 348, 107-114.

46 E. Plasari, P.H. Grisoni and J. Villermaux, Chem. Eng. Res. Des. 1997, 75, 237-244.

47 S. Sant, S. Poulin and P. Hildgen, J. Biomed. Mater. Res. Part A 2008, 87A, 885-895.

48 D. Bazile, C. Prud'homme, M.T. Bassoullet, M. Marlard, G. Spenlehauer and M. Veillard, J. Pharm. Sci. 1995, 84, 493-498.

49 J.-M. Rabanel, P. Hildgen and X. Banquy, J Control. Release 2014, 185, 71-87.

50 G. Riess, Prog. Polym. Sci. 2003, 28, 1107-1170.

51 K. Devanand and J.C. Selser, Macromolecules 1991, 24, 59435947.

52 P.G. de Gennes, Macromolecules 1980, 13, 1069-1075.

53 J.L. Perry, K.G. Reuter, M.P. Kai, K.P. Herlihy, S.W. Jones, J.C. Luft, M. Napier, J.E. Bear and J.M. DeSimone, Nano Lett. 2012, 1, 304-5310.

54 P.G. de Gennes, Adv. Colloid Interface Sci. 1987, 27, 189-209.

55 S. Si-Mohamed, D. Bar-Ness, M. Sigovan, V. Tatard-Leitman, D.P. Cormode, P.C. Naha, P. Coulon, L. Rascle, E. Roessl, M. Rokni, A. Altman, Y. Yagil, L. Boussel and P. Douek, Eur. Radiol. Exp. 2018, 2, 34.

56 I. Riederer, S. Si-Mohamed, S. Ehn, D. Bar-Ness, P.B. Noël, A.A Fingerle, F. Pfeiffer, E.J. Rummeny, P. Douek and D. Pfeiffer, PLoS One 2019, 14, e0212679.

57 F. Alexis, E. Pridgen, L.K. Molnar and O.C. Farokhzad, Mol. Pharm. 2008, 5, 505-515.

58 F. Laredj-Bourezg, Y. Chevalier, O. Boyron and M.-A. Bolzinger, Colloids Surf. A: Physicochem. Eng. Aspects 2012, 413, 252259.

59 F. Laredj-Bourezg, M.-A. Bolzinger, J. Pelletier, J.-P. Valour, M. R. Rovère, B. Smatti and Y. Chevalier, Int. J. Pharm. 2015, 496, 1034-1046.

60 G. Agusti, O. Jordan, G. Andersen, E. Doelker and Y. Chevalier, J. Appl. Polym. Sci. 2015, 132, 41791.

61 H. Fessi, J.-P. Devissaguet, F. Puisieux and C. Thies, US patent US5118528 A1 (1992).

62 D. Quintanar-Guerrero, E. Allémann, H. Fessi and E. Doelker Drug Dev. Ind. Pharm. 1998, 24, 1113-1128. 